ARTÍCULO

\title{
EL IMPACTO DE LA PRESA LAS MERCEDES EN SANTA CATALINA DEL ÁLAMO Y EL PUEBLO DE PASAJE, EN EL ORIENTE DE DURANGO
}

\author{
THE IMPACT OF LAS MERCEDES DAM \\ IN SANTA CATALINA DEL ALAMO AND PASAJE TOWN, \\ EAST OF DURANGO
}

\author{
Daniel GUILlermo Rodríguez BARRAGÁN \\ Universidad Juárez del Estado de Durango \\ danielguillermorb@hotmail.com
}

\section{Resumen}

El presente trabajo expone la dinámica que se vivía en el oriente de Durango a finales del siglo XIX y principios del xx, etapa marcada por la llegada del ferrocarril, y la manera en que enmarcados en dicho contexto, la familia Martínez del Río, dueña del latifundio más grande de la entidad, Santa Catalina del Álamo, se apropió del agua del afluente de El Zorrillo, gracias a la construcción de la presa Las Mercedes. Lo cual derivó en un reajuste en sus relaciones con los habitantes del pueblo de Pasaje, quienes consideraban que se les despojaba de su tierra y agua.

Palabras clave: agua; pueblo; tierra; latifundio; ferrocarril.

Abstract

The present work is aimed to describe the ways of life in the Eastern part of Durango at the end of 19th century and the beginning of 20th's, an epoch signaled by the railroad arrival. In particular, it describes the context and means by which the Martínez del Río family, owner of Santa Catalina del Alamo, the biggest Durango's latifundium, appropriated El Zorrillo stream at the time of Las Mercedes Dam construction, an event that compelled a rearrangement of the relations between the Martínez del Río family and the Pasaje town inhabitants, who considered that the former had deprived them from their land and water.

Key words: water; town; land; latifundium; railroad.

Información del artículo

Recibido: 30 de septiembre de 2019.

Aceptado: 27 de enero de 2020.

DOI: 10.22201/iih.24485004e.2020.59.70984 
Estudiar la última etapa del Porfiriato generalmente nos remite a la idea de la lucha por la tenencia de la tierra. A partir de esta generalidad hay que tomar en cuenta las características de cada región del país. En el norte de México siempre ha habido menos población que en el centro, lo cual tiene causas geográficas y climatológicas: amplias zonas desérticas, pocos ríos y una lluvia escasa. Dichas peculiaridades le imprimieron su sello a la manera en que se utilizaban y disputaban los recursos naturales a inicios del siglo xx. Un ejemplo fueron los intentos por acaparar las fuentes de agua para explotarlas a su máxima capacidad y desarrollar una tecnología que permitiera controlar su acceso. En el presente texto se analiza un caso paradigmático en Durango, el de la presa Las Mercedes.

Dicho estudio se encuentra dividido en cuatro apartados, en el primero, "Una gran propiedad en el desierto", se hace un recorrido desde el origen virreinal del latifundio de Sata Catalina del Álamo, hasta su venta a la familia Martínez del Río a finales del siglo xıx, se habla de su diversidad productiva y de cómo las condiciones geográficas y climatológicas, como la falta de agua, sumado a su gran tamaño, evitaban que sus dueños aprovecharan el potencial de su propiedad.

En el segundo apartado, “Agua, latifundio y ferrocarril”, se expone el escenario regional de principios del siglo $\mathrm{xx}$, caracterizado por una disputa entre terratenientes de Durango y Coahuila por el agua del Río Nazas, en donde quienes tenían afluentes de éste en sus propiedades podían ver disminuir la cantidad del vital líquido que podían utilizar; al mismo tiempo, el tendido de vías férreas generaba las posibilidades de colocar las mercancías de los latifundistas en diversas partes de México y Estados Unidos, lo que volvía imprescindible explotar a su máxima capacidad las grandes propiedades. Lo cual, a su vez, explica la decisión de los Martínez del Río de construir una presa.

Como tercer apartado tenemos "Construcción de Las Mercedes", donde se analiza cómo fueron las labores de edificación de la presa, el papel de los ingenieros involucrados, y cómo esta construcción fue un punto de inflexión en la relación de los diversos dueños del latifundio con los habitantes del pueblo de Pasaje, la que se había caracterizado por las disputas territoriales y la contratación de mano de obra.

Finalmente, en el último apartado, "Consecuencias", se estudia cómo la construcción de Las Mercedes influyó decididamente en el desarrollo económico del latifundio, al permitir a sus dueños producir algodón y guayule, gracias a lo cual obtuvieron mayores ganancias en mercados nacionales 
e internacionales; esta situación provocó la participación de los habitantes de Pasaje en la Revolución y el posterior reparto de la tierra que había formado Santa Catalina del Álamo, el cual no terminó con los conflictos por el acaparamiento del agua, protagonizados en las décadas siguientes por habitantes de pueblos y ejidatarios.

\section{Una gran propiedad en el desierto}

El oriente del actual estado de Durango, que se observa en el mapa 1 siempre ha sido una región desértica, donde el ser humano ha encontrado dificultades para establecerse. Los pueblos originarios eran nómadas que recorrían ese territorio en busca de los elementos de subsistencia. Después de la llegada de los españoles, en el contexto de la lucha contra los indios bárbaros, el mayor éxito de los primeros en términos de poblamiento fue la fundación de presidios y la creación de mayorazgos, ${ }^{1}$ de los cuales el más importante fue el de San Miguel de Aguayo establecido a finales del siglo XVII. ${ }^{2}$ Desde aquellos tiempos hasta las últimas décadas del siglo XIX no hubo un incremento considerable de la población, ${ }^{3}$ pero sí cambios

${ }^{1}$ Para un estudio en profundidad de los problemas de poblamiento en el norte y oriente del actual estado de Durando durante el virreinato, que generaron en dicho territorio una sociedad de frontera nómada con profundas repercusiones en la estructura familiar, organización política y militar, así como en las dinámicas económicas, véanse: Peter Gerhard, $L a$ frontera norte de la Nueva España (México: Universidad Nacional Autónoma de México, Instituto de Investigaciones Históricas, 1996); y Chantal Cramaussel, Poblar la frontera: la provincia de Santa Bárbara en Nueva Vizcaya durante los siglos XVI y XVII (Zamora: El Colegio de Michoacán, 2006).

${ }^{2}$ Esta propiedad, que se extendía por los actuales estados de Durango y Coahuila, fue fundada por Agustín de Echevers; llegó a su máximo esplendor con el matrimonio entre María Josefa Echevers y Francisco de Valdivieso en 1735, esto unió dicho mayorazgo con el de San Pedro del Álamo. Para un mayor acercamiento al estudio de las ventajas y desventajas económico-administrativas que se derivaban de las grandes propiedades antes de la consumación de la Independencia de México, véase: María Vargas-Lobsinger, Formación y decadencia de una fortuna: los mayorazgos de San Miguel de Aguayo y San Pedro del Álamo, 15831823 (México: Universidad Nacional Autónoma de México, Instituto de Investigaciones Históricas, 1992), 15-79.

${ }^{3}$ Para un mayor entendimiento sobre los problemas de Durango para incrementar su población, entre los que destacaron las epidemias, la lejanía de los más importantes centros comerciales que se desarrollaban en el centro del país, la guerra casi permanente contra los grupos de indios bárbaros y las crisis en la producción minera y de alimentos como maíz y frijol, véase: Miguel Felipe de Jesús Vallebueno Garcinava, “Epidemias y crisis de subsistencia en Durango. 1622-1918”, en Historia del estado de Durango, v. III, Siglo XIX, coord. de 
importantes en relación con la configuración de la propiedad, ya que los presidios se convirtieron en pueblos y el mayorazgo se dividió en haciendas.

Al final de la guerra de Independencia el mayorazgo de San Miguel de Aguayo entró en crisis. Poco a poco se fue fraccionando en grandes haciendas que pasaron por diversas manos, tanto laicas como eclesiásticas, lo que configuró una élite de terratenientes en todo el oriente de Durango; ${ }^{4}$ pero para fines de este trabajo nos centraremos en el Partido de Cuencamé que se muestra en el mapa $2 .{ }^{5}$

Para mediados del siglo XIX uno de los latifundios más importantes en dicho partido era el de Santa Catalina del Álamo; esta propiedad, que era la más grande de Durango con sus 418193 hectáreas, ${ }^{6}$ perteneció a la Compañía Limitada Mexicana de Hipotecas de Terrenos e Inversión, de origen inglés, encabezada por Sir Charles Clifford, Conde de Kintoro, aristócrata escocés con inversiones en lugares tan distintos como México, Australia o Nueva Zelanda. ${ }^{7}$ En esta época Santa Catalina del Álamo estaba formada por siete haciendas, las cuales a partir del tipo de tierra que disponían

María Guadalupe Rodríguez López (Durango: Universidad Juárez del Estado de Durango, Instituto de Investigaciones Históricas, 2013), 127-149.

${ }^{4}$ A finales del siglo xix y principios del xx la élite de terratenientes del oriente de Durango estaba formada por un puñado de familias, entre las que se pueden mencionar Curbelo, Nava, Santa Marina, Torres, Moller, Moncada, González Saravia, Martínez del Río y López Negrete. Dichas familias, si bien sus principales inversiones eran sus latifundios, también se debe mencionar que tenían una actividad económica diversificada, ya que sus apellidos se encuentran ligados a la inversión en la minería, la industria textil, el comercio y el ferrocarril. De la misma manera, desempeñaron cargos políticos importantes, pues algunos de sus miembros llegaron a ser diputados locales, presidentes municipales e incluso gobernadores de Durango durante el Porfiriato y la etapa inmediatamente posterior.

${ }^{5}$ En el cambio del siglo XIX al xx Durango se dividía en partidos, municipalidades y jefaturas de manzana; se establecieron 43 municipalidades y 13 partidos. El Partido de Cuencamé al norte colindaba con los partidos de Nazas y Mapimí; al este, con el partido de San Juan de Guadalupe y el estado de Coahuila; al sur, con el estado de Zacatecas y el partido de Nombre de Dios; y al oeste, con el partido de San Juan del Río. En cuanto a su división interna se encontraba constituido por tres municipalidades: Cuencamé, Peñón Blanco y Santa Clara. "Ley de División Territorial”, Periódico Oficial del Gobierno del Estado de Durango, Durango, 21 de diciembre de 1905.

${ }^{6}$ Memoria presentada al $\mathrm{H}$. Congreso del estado por el gobierno del mismo, sobre los actos de administración pública durante el periodo del 16 de septiembre de 1904 al 16 de septiembre de 1906, Imprenta de la Mariposa, Durango, 1906, Anexo 48, Archivo Histórico del Estado de Durango (en adelante AHED), Fondo Secretaría de Gobierno, Sección Archivo.

${ }^{7}$ Miguel Felipe de Jesús Vallebueno Garcinava, Haciendas de Durango (Durango: Gobierno del Estado de Durango/Tonalco/Universidad Juárez del Estado de Durango, 1997), 127. 
Mapa 1

Oriente De DURAngo

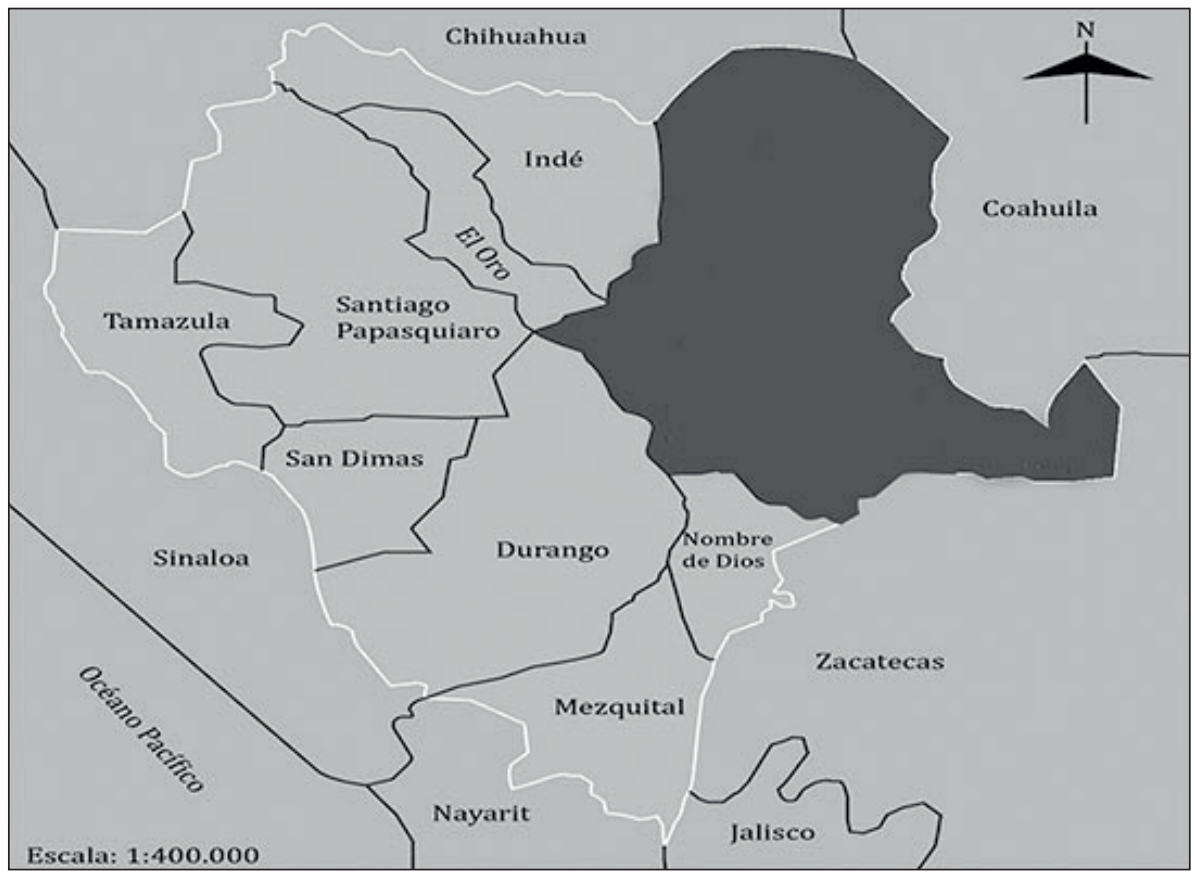

FUENTE: elaboración propia

enfocaban su producción en diferentes ámbitos: en las tierras de temporal de Santa Catalina se cultivaba maíz y frijol; en la de agostadero de las haciendas de Álamo y Covadonga se criaban caballos, mulas, cabras y ovejas; en Mercedes, Guadalupe y Cruces se tenían campos de riego con plantíos de algodón y trigo; mientras que Pasaje tenía una economía mixta. ${ }^{8}$

La propiedad fue vendida en 1897 a Pablo Martínez del Río Castiglione, ${ }^{9}$ quien además de ser un importante abogado de compañías ferrocarrileras

${ }^{8}$ David Walker, “un estudio estadístico de la economía agrícola de Cuencamé, México: 1895-1911” (ponencia, Taller de Historia Económica, Universidad de Indiana, Bloomington, Indiana, 1996), 13. Documento sin publicar en resguardo del Instituto de Investigaciones Históricas de la Universidad Juárez del Estado de Durango. Agradezco a la maestra María Guadalupe Rodríguez López, investigadora de dicho instituto, el haberme proporcionado esta información.

${ }^{9}$ Pedro Salmerón Sanginés, La División del Norte. La tierra, los hombres y la historia de un ejército del pueblo (México: Planeta, 2006), 163. 
Mapa 2

Partido de Cuencamé

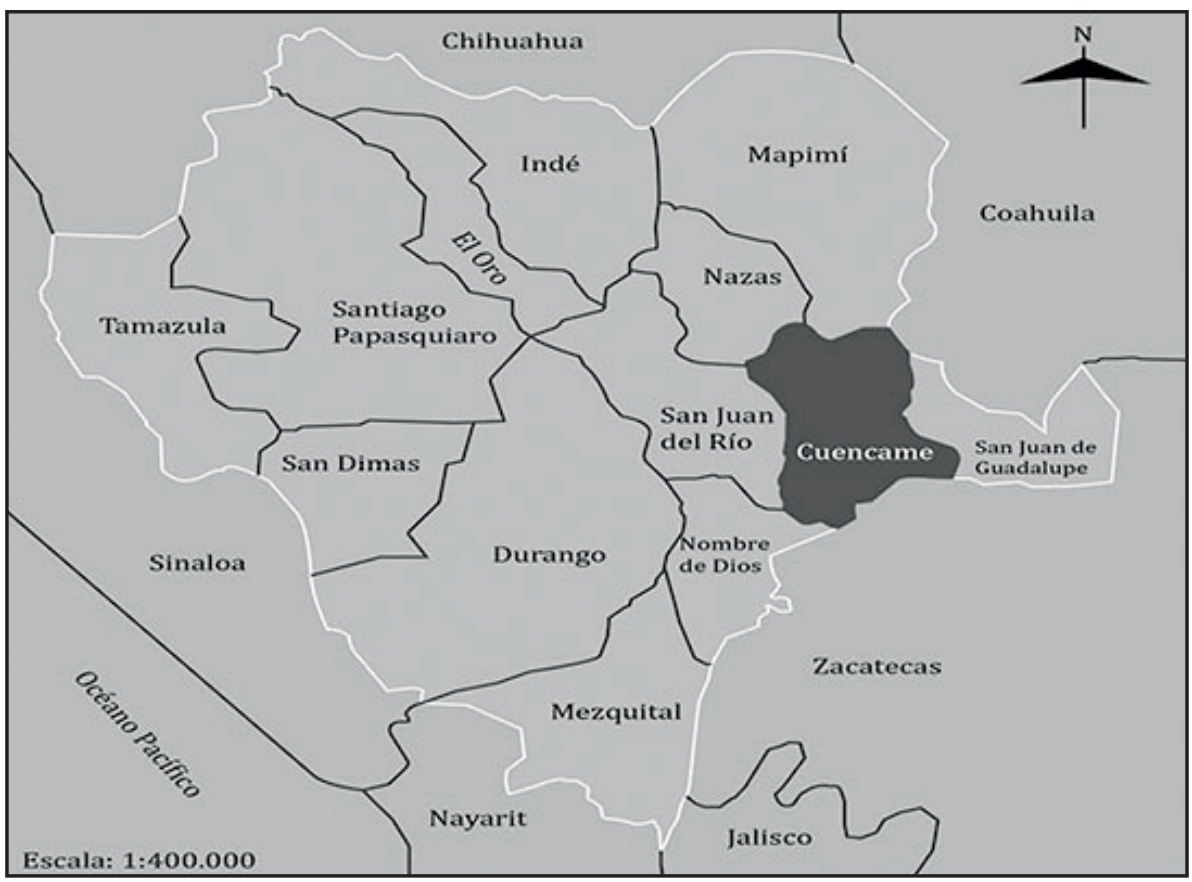

FUENTE: elaboración propia

era el patriarca de una familia de comerciantes de origen panameño llegada a México en 1824, la cual a lo largo del siglo xix invirtió en negocios bancarios, textileros y mineros en Jalisco, Nayarit y Durango, para finalmente asentarse en esta última entidad donde la familia reunió su capital para comprar Santa Catalina del Álamo, buscando abandonar su diversificación en los negocios y centrarse en la exportación agropecuaria a Estados Unidos. ${ }^{10}$ Inversión que los Martínez del Río seguramente querían llevar a buen puerto gracias a tres factores: 1) el apoyo de políticos nacionales de primer nivel, como José Yves Limantour, quien tuvo una larga amistad con Pablo Martínez del Río;11 2) el respaldo de otros terratenientes locales,

${ }^{10}$ David Walker, Parentesco, negocios y política. La familia Martínez del Río en México, 1823-1867 (México: Alianza Editorial, 1991), 304.

${ }^{11}$ José Y. Limantour a Amelia Zamacona de Martínez del Río, París, 15 de diciembre de 1915, Centro de Estudios de Historia de México del Grupo CaRso (en adelante CEHM), Fondo CDLIV, Serie 2a., caja 19. 
como las familias Bracho o Saravia con quienes ya tenía negocios comerciales; ${ }^{12}$ y 3) la buena labor del administrador Francisco Gómez Palacio a quien pusieron al frente del latifundio, ya que los Martínez del Río pasaban la mayor parte de su tiempo entre las ciudades de Durango y México; así como en viajes por Europa y Estados Unidos. ${ }^{13}$

El deseo de invertir para aumentar la capacidad productiva de Santa Catalina del Álamo, aprovechando las condiciones económicas y políticas generadas por el Porfiriato, se enfrentó con la realidad de la geografía, específicamente con la falta de agua. Al ser un latifundio de tan grandes dimensiones, no solamente ofrecía oportunidades de generar ganancias y prestigio social, sino también se convertía en un riesgo para el capital familiar. Para que fuera rentable se tenía que utilizar a su mayor capacidad la tierra de buena calidad, lo que en el contexto del oriente de Durango se traducía en la explotación intensiva de los recursos hídricos.

La respuesta de los Martínez del Río a este reto fue la construcción de la presa Las Mercedes, el cual fue el proyecto de infraestructura emprendido por un particular más importante no sólo en el latifundio de Santa Catalina del Álamo, sino en todo el estado de Durango durante el Porfiriato. Antes de estudiar con detenimiento dicha construcción, es conveniente analizar a grandes rasgos en qué situación se encontraba la explotación de los recursos hídricos en la entidad, así como la dinámica de dicho latifundio a comienzos del siglo xx, cuando se inició la construcción de Las Mercedes.

\section{Agua, latifundio y ferrocarril}

Durante el Porfiriato, en el estado de Durango no sólo la tierra, sino también el agua, se convirtió en un bien que generó constantes conflictos entre diversos grupos de terratenientes y compañías mineras. El caso más representativo, por su duración, importancia económica en el ámbito nacional y repercusiones legales, lo constituyó la lucha por el control del río Nazas, el cual, como se muestra en el mapa 3, nace en la Sierra Madre Occidental,

${ }^{12}$ Walker, Parentesco, negocios y política..., 299.

${ }^{13}$ David Walker, “Un terrateniente urbano en Durango 1897-1911” (ponencia, Universidad de Radford, Virginia, s. f.), 19. Documento sin publicar en resguardo del Instituto de Investigaciones Históricas de la Universidad Juárez del Estado de Durango. Agradezco a la maestra María Guadalupe Rodríguez López, investigadora de dicho instituto, el haberme proporcionado esta información. 
atraviesa el norte de Durango y desagua en la Laguna del Mayrán en Coahuila. Durante el tránsito del siglo XIX al XX se convirtió en una pieza fundamental para el desarrollo de las haciendas en ambos estados, principalmente algodoneras. ${ }^{14}$

En 1881, debido a la construcción de presas por parte de terratenientes durangueños como la familia Lavín, disminuyó la cantidad de agua que llegaba a los hacendados de Coahuila, lo cual desencadenó un conflicto por apropiarse del vital líquido entre los agricultores de ambos estados. Esta lucha se agravó en 1885 con la entrada de la Compañía Agrícola de Tlahualilo, de capital regiomontano, británico y estadounidense, que contaba con el apoyo del presidente Díaz. Para 1888 la disputa había tomado tal proporción que el gobierno federal decidió asumir el control de los principales cuerpos y corrientes de agua del país. Esta medida no acabó con los enfrentamientos, debido al trato preferencial que seguía recibiendo la Compañía de Tlahualilo y por las frecuentes sequías que volvían inconstante el agua que recibían en Coahuila, lo que llevó a que resurgiera la violencia a partir de1908. ${ }^{15}$

Para enero de 1900 Pablo Martínez del Río había terminado de depositar en los bancos ingleses el pago de los intereses generados por la compra de Santa Catalina del Álamo. ${ }^{16}$ Propiedad que en un inicio intentó hacer producir con las estrategias que los dueños de grandes propiedades habían utilizado desde la época virreinal, como el arrendamiento de la tierra que el latifundista no podía explotar; ${ }^{17}$ a lo que se sumó rápidamente el interés de otros empresarios de las regiones aledañas, no por tierra, sino por el agua dentro del latifundio, la que se quería para el funcionamiento de la

14 Pastor Rouaix, Geografía del estado de Durango (México: Secretaria de Agricultura y Fomento, 1929), 15-16.

15 Para un mayor estudio sobre cómo esta situación ayudó a establecer las pautas de un conflicto entre algunos sectores de la élite de terratenientes de la Comarca Lagunera y el gobierno nacional dirigido por Porfirio Díaz, así como entre pequeños y medianos propietarios con los dueños de grandes propiedades, véase: Guadalupe Villa Guerrero, “¿Interés público o beneficio particular? El agua en la Comarca Lagunera (1881-1910)”, Secuencia. Revista de Historia y Ciencias Sociales, n. 39 (1997): 41-48, https://doi.org/10.18234/secuencia.v0i39.590.

${ }^{16}$ Recibo manuscrito firmado por Edward John Gardiner, s. 1., 1 de enero de 1900, CEHM, Fondo DCXXIII, legajo 34, carpeta 02, documento 23.

${ }^{17}$ Contrato manuscrito firmado por Alberto G. Saravia, José Casas, Otilios Ramírez y José Refugio Reyes, Hacienda del Álamo, 7 de diciembre de 1900, CEHM, Fondo DCXXIII, legajo 18, carpeta 02, documento 11 . 
Mapa 3

Fuentes de agua del estado de Durango

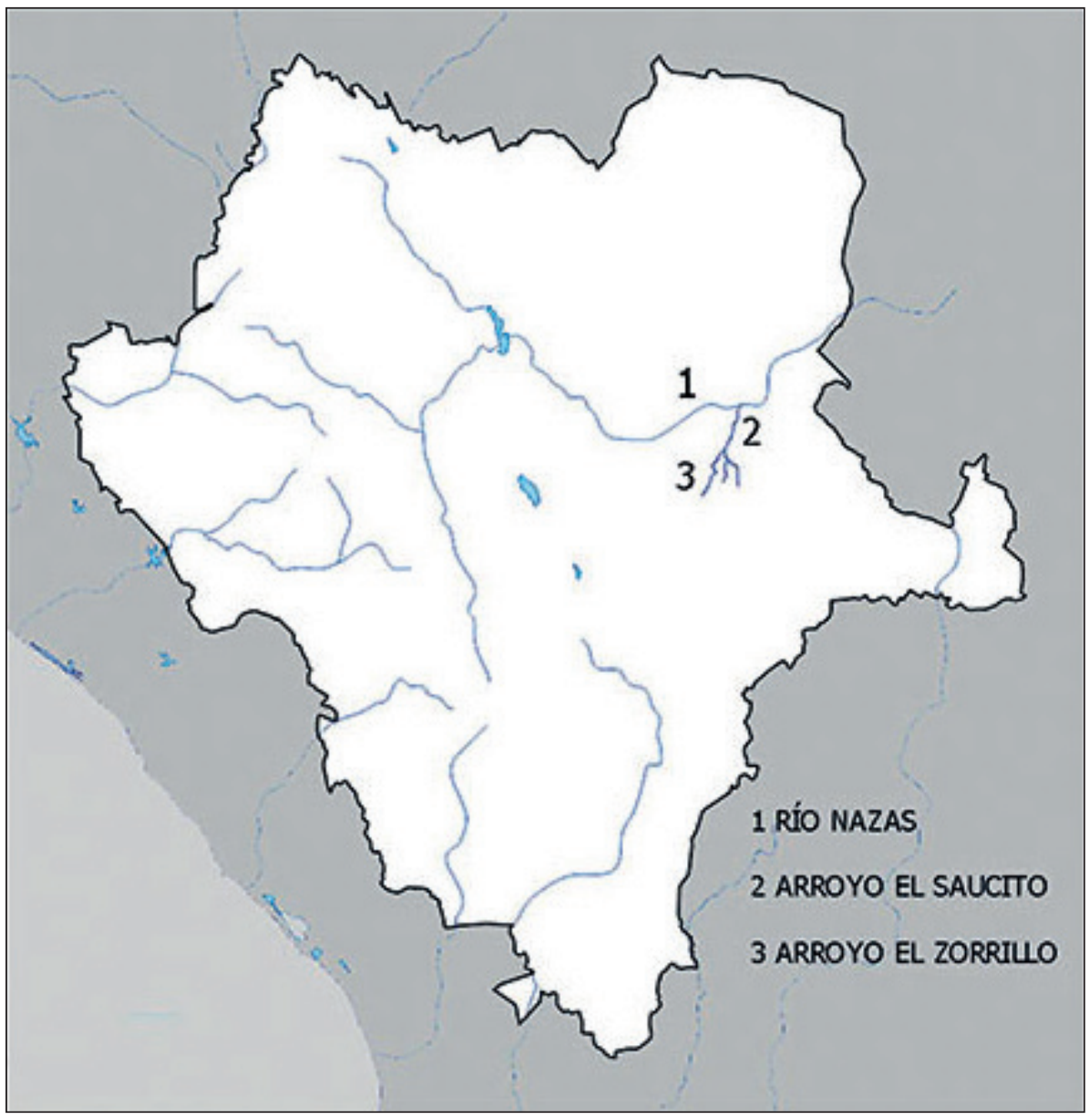

FUENTE: elaboración propia 


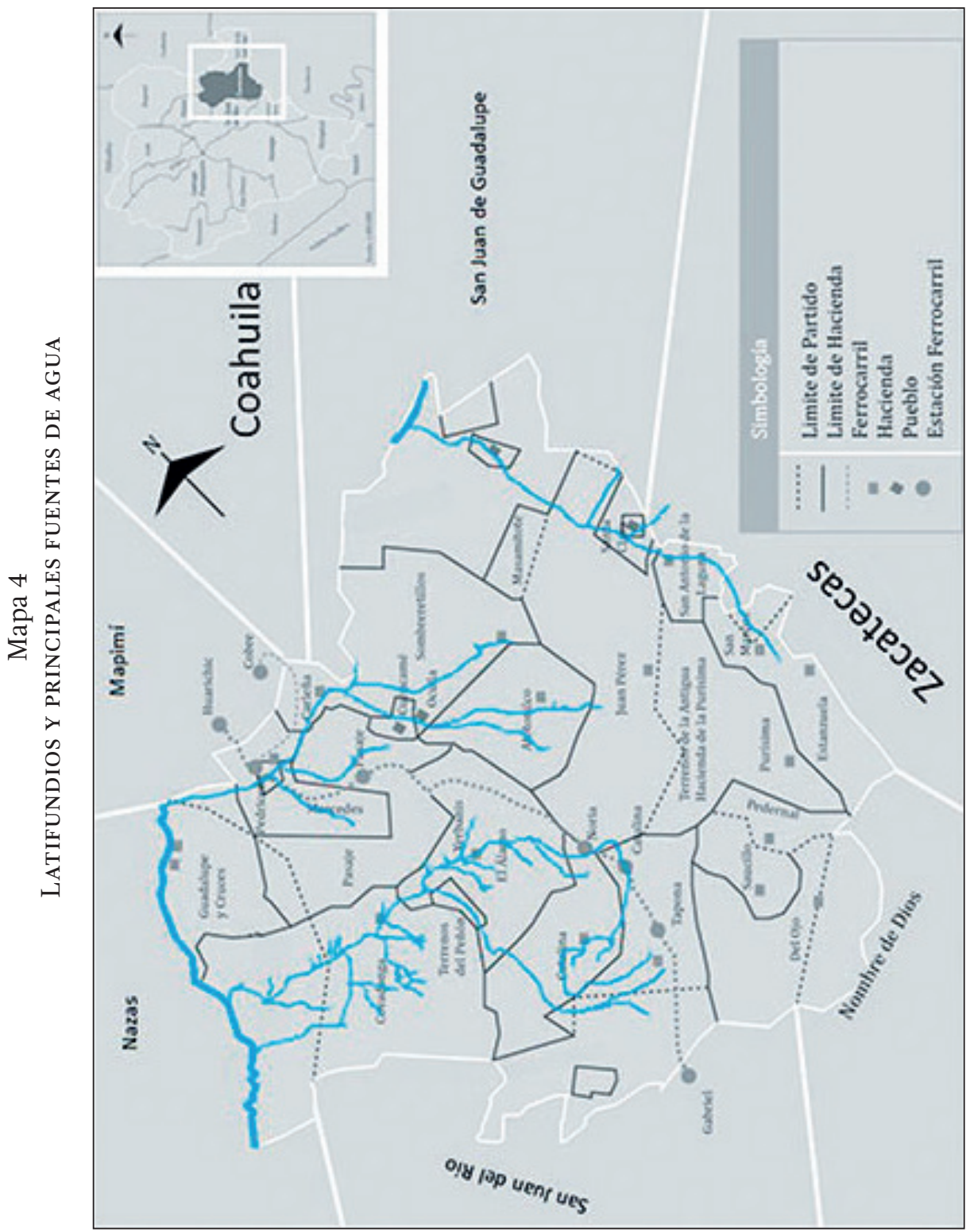

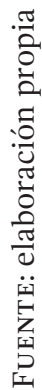


maquinaria. ${ }^{18}$ Debido a que el río Nazas por su paso por el oriente de $\mathrm{Du}$ rango, como se muestra en el mapa 4, desprendía una serie de brazos de agua sobre varias haciendas del Partido de Cuencamé, Martínez de Río, al comprar un latifundio que recibía estos depósitos del vital líquido, se vio afectado a causa de la disputa por el Nazas.

Justo cuando comenzaba a asumir el control de su nueva propiedad, la lucha por el mencionado afluente estaba en uno de sus momentos más álgidos. En 1891 los representantes de la Compañía de Tlahualilo adquirieron la hacienda de San Fernando -famosa por tener la presa del mismo nombre, que era de las más importantes en la región-, lo que provocó inconformidades de los diferentes grupos de rivereños y la promulgación de un nuevo reglamento para la utilización de las aguas del Nazas en 1895; lo cual, aunado a las catástrofes naturales como las sequías, heladas, desbordamientos y plagas, provocó que en los siguientes años siguiera habiendo conflictos. ${ }^{19}$ A partir de este escenario las reminiscencias de agua que llegaban a Cuencamé se volvieron cada vez más valiosas para todos los actores sociales.

Un año después de que la Tlahualilo compró la hacienda de San Fernando, en 1892, el humo de las locomotoras anunció la llegada del Ferrocarril Internacional Mexicano a la ciudad de Durango, cuyo tendido de vías, como muestra el mapa 5, al unir la capital del estado con Torreón, atravesó el Partido de Cuencamé. ${ }^{20}$ Las empresas ferrocarrileras fueron reconocidas por los poderes locales como actores sociales importantes; tales compañías lejos de ser combatidas por los terratenientes establecieron una relación con ellos, la cual estuvo marcada por la mutua dependencia y complicidad, en donde los latifundistas buscaron sacar provecho de la nueva interconexión abierta por el ferrocarril. ${ }^{21} \mathrm{El}$ quedar unidos a la Comarca Lagunera significaba tener vía libre, gracias a otros tramos de vía, al mercado estadounidense.

${ }^{18}$ Carta de L. M. Johnson a Pablo Martínez del Río, Torreón, 5 de diciembre de 1900, CEHM, Fondo DCXXIII, legajo 25, carpeta 02, documento 13.

${ }^{19}$ Lourdes Romero Navarrete, "Conflicto y negociación por el agua del Nazas, 18881936. Del dominio público a la propiedad nacional”, Región y Sociedad, n. 36 (2006): 156, https://doi.org/10.22198/rys.2006.36.a587.

${ }^{20}$ Antonio Arreola Valenzuela, Durango, más de un siglo sobre rieles (Durango: Universidad Juárez del Estado de Durango, Instituto de Investigaciones Históricas, 1992), 51.

${ }^{21}$ Lorenzo M. Johnson a Juan Manuel Flores, Cd. Porfirio Díaz, 19 de julio de 1892, AHED, Fondo Secretaría General de Gobierno, Sección Siglo XIX, Serie Correspondencia de Gobernadores. 


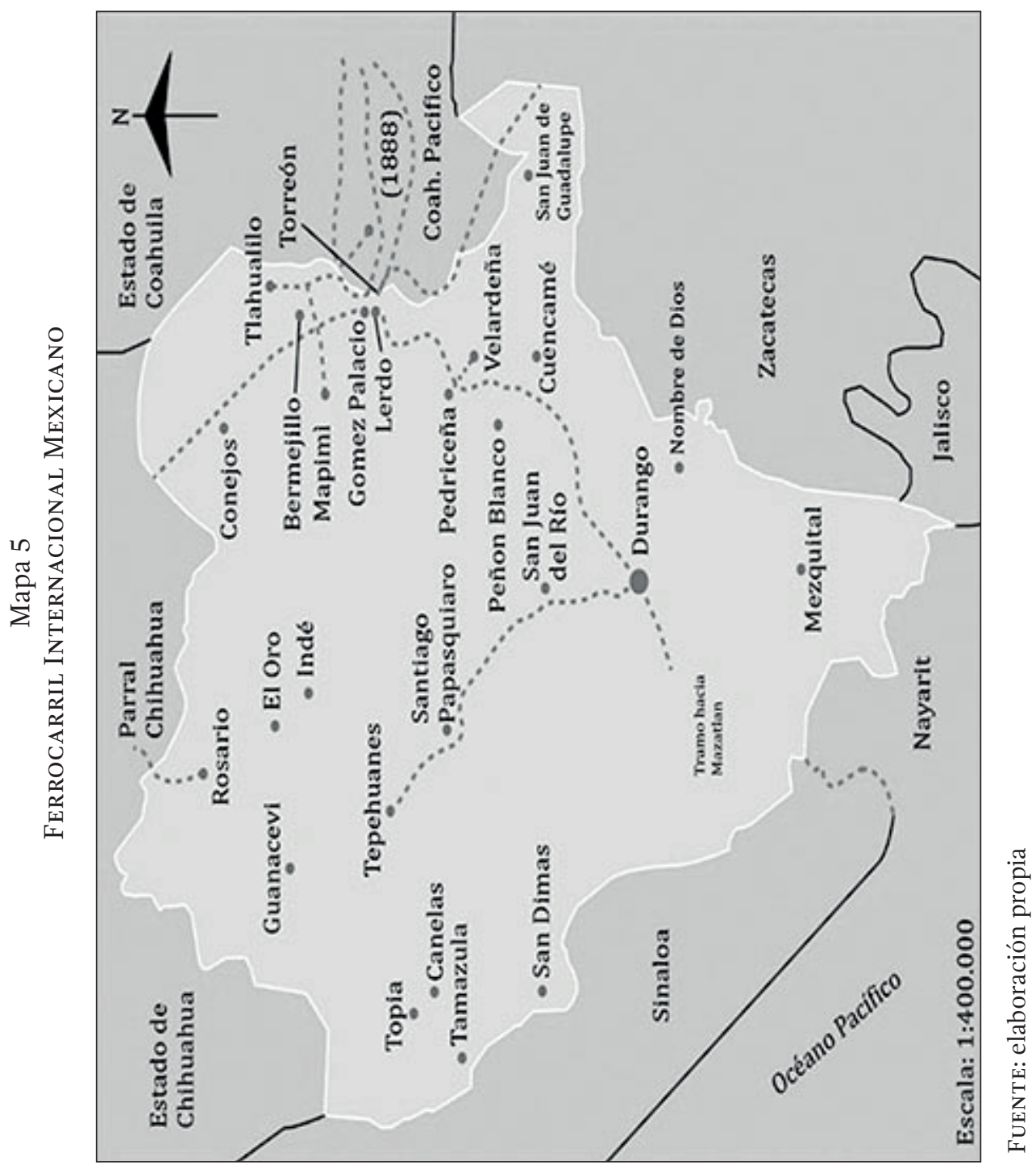


Entre los empresarios que se dieron cuenta de esta oportunidad estuvieron los distintos dueños de Santa Catalina del Álamo. Desde el comienzo de los trabajos se proyectó que el ferrocarril atravesara los territorios de este latifundio para llegar a la capital, por lo que el Conde de Kintoro otorgó la concesión necesaria a la compañía ferrocarrilera; ${ }^{22}$ así como para establecer ramales a importantes centros mineros como Velardeña. ${ }^{23}$ Lo cual muestra el entrelazamiento entre diferentes sectores económicos que terminaron por consolidar a una élite empresarial extranjera, ya que el Ferrocarril Internacional Mexicano - con su gerente L. M. Johnson a la cabeza - estaba constituido por inversionistas de la banca estadounidense ${ }^{24}$ con fuerte presencia en la Comarca Lagunera; ${ }^{25}$ mientras que Velardeña era propiedad de la ASARCo (American Smeltine and Refining Co.), empresa también de capital estadounidense. ${ }^{26}$ Dinámica en donde los terratenientes intentaban insertase como socios, proveedores de materias primas e intermediarios con el gobierno local.

${ }^{22}$ Francisco Soriano a Porfirio Díaz, Durango, 12 de junio de 1891, Archivo Porfirio Díaz de la Universidad Iberoamericana (APD), legajo XVI, documento 005067.

${ }^{23}$ Porfirio Díaz a Juan Manuel Flores, México, 7 de abril de 1892, AHED, Fondo Secretaría General de Gobierno, Sección Siglo xix, Serie Correspondencia de Porfirio Díaz.

${ }^{24}$ Entre los que destacaban: Coahuila-Durango Development Company, el Nacional City Bank, el Nacional Morgan Bank y el First National Bank.

${ }^{25}$ Las políticas de inversiones de las compañías ferrocarrileras las convirtieron en importantes actores económicos en el estado de Durango, ya que sus miembros además de los fuertes intereses en la industria minera en la entidad, en donde junto con el mineral de Velardeña destacaba el de Cerro de Mercado en la capital, también estaban inmiscuidos en la explotación de madera en el occidente del estado de Durango. Para saber más sobre este tema, véase: Antonio Arreola Valenzuela, "Construcción del sistema ferroviario e inversión estadounidense en Durango", en Historia del estado de Durango, v. III, Siglo XIX, coord. de María Guadalupe Rodríguez López (Durango: Universidad Juárez del Estado de Durango, Instituto de Investigaciones Históricas, 2013); y John Hart, "Durango: el crecimiento del capitalismo norteamericano durante el Porfiriato". En Historia del estado de Durango, v. III, Siglo XIX, coord. de María Guadalupe Rodríguez López (Durango: Universidad Juárez del Estado de Durango, Instituto de Investigaciones Históricas, 2013).

${ }^{26}$ La presencia de esta compañía minera se puede rastrear en estados como Nuevo León o Aguascalientes, en donde estableció diferentes funciones; por ejemplo, mientras en Durango se dedicaban exclusivamente a la extracción de metales, en otras partes del país realizaba el proceso de fundición para después sacar el producto de México y posicionarlo en el mercado estadounidense. Para estudiar más sobre los orígenes de esta empresa y su influencia en la economía mexicana, véase: Luz María Uhthoff, "La American Smeltine and Refining Co. (ASARCO) en México 1890-1930" (tesis de licenciatura, Universidad Nacional Autónoma de México, 1983). 
Dicha postura fue mantenida por los Martínez del Río, quienes buscaron tener buenas relaciones con los representantes del Ferrocarril Internacional Mexicano. Una muestra es el contrato que celebraron en 1898 para establecer líneas telefónicas entre las diferentes haciendas de Santa Catalina del Álamo aprovechando el tendido que ya había hecho la empresa del ferrocarril, para lo cual asumían los gastos de su construcción y reparación, se eximía a la empresa de la responsabilidad en cualquier accidente y se le permitía a ésta retirar la autorización a los Martínez del Río en cualquier momento. ${ }^{27}$ Estas condiciones tan desequilibradas muestran el deseo de los terratenientes por no molestar a quienes les brindaban nuevas posibilidades de crecimiento económico.

Al iniciar el siglo xx Pablo Martínez del Río se encontraba al frente de un negocio que al mismo tiempo ofrecía importantes riesgos y oportunidades. Por un lado estaba el gasto económico que había significado el pago de los intereses por la compra del latifundio y su mantenimiento; pero por otro, la interconexión regional e internacional traída por el ferrocarril abría las puertas a ganancias sin precedentes para quien supiera explotar los recursos naturales a su alcance. En medio de estas dos situaciones se encontraba la disputa por el control de la corriente del río Nazas, que amenazaba con limitar el potencial de producción en el oriente de Durango, lo cual era un evidente riesgo para los dueños de Santa Catalina del Álamo, cuyo territorio era atravesado por el arroyo del Saucito, uno de los principales afluentes del Nazas $^{28}$ (véase el mapa 3). En este escenario, los Martínez del Río apostaron por la inversión: ya no era suficiente con el arrendamiento de tierra o agua, ahora ellos tenían que explotar su nuevo latifundio utilizando nueva tecnología.

\section{Construcción de Las Mercedes}

Construir una presa para asegurar la mayor cantidad posible de agua resultaba algo lógico en el oriente de Durango, si se quería hacer frente a la nueva realidad económica de la última etapa del Porfiriato. Ya se habían hecho algunas en la región de la Comarca Lagunera en el contexto de la

${ }^{27}$ Contrato celebrado entre L. M. Johnson y Pablo Martínez del Río, s. 1., 22 de septiembre de 1898, CEHM, Fondo DCXXIII, legajo 18, carpeta 02, documento 44.

${ }^{28}$ Rouaix, Geografía del estado de Durango..., 158. 
lucha por el río Nazas, y en Santa Catalina del Álamo tenían tanto la necesidad como el capital para llevar a cabo dicha empresa. Pero los Martínez del Río se iban a topar aparentemente con un fuerte obstáculo al momento de querer construir su propia presa: los habitantes del pueblo del Real Presidio del Pasaje. Después de todo, donde hay agua hay centros de población, no sólo latifundios, sino de diversos tipos.

Como se mencionó anteriormente, los mayorazgos se convirtieron en haciendas y los presidios en pueblos. Uno de ellos fue el pueblo de Pasaje, del que hay noticias de su establecimiento legal en 1687, cuando en pública subasta organizada por el juzgado eclesiástico los pobladores que ya residían en ese lugar compraron la tierra. En 1807, los dueños del latifundio de Santa Catalina del Álamo ocuparon terrenos de Pasaje, esto se resolvió legalmente cuando los juzgados de Guadalajara ordenaron la restitución a los habitantes del pueblo, pero sin que sucediera en la práctica. En 1889, la hacienda fue adquirida por la compañía inglesa ya mencionada, la que prosiguió con el retiro de mojoneras para ocupar más tierras de la comunidad. Lo cual se incrementó cuando Pablo Martínez del Río compró la propiedad, al grado que los vecinos se quejaban de no tener los indispensables elementos para su subsistencia, desarrollo y progreso; esta situación desató choques violentos entre los habitantes de Pasaje y los trabajadores y arrendatarios del latifundio. ${ }^{29}$

El representante legal de los vecinos de Pasaje (y de los de Peñón Blanco), el señor Simón Yiverino, no especificó en su correspondencia cuáles eran esos "indispensables elementos", pero se sabe que sus representados ya no podían ni cultivar ni poner a pastar su ganado, esto indica que la tierra del pueblo era de buen tamaño y de calidad, lo cual era posible gracias a que contaba con una buena dotación de agua. El incremento de la agresividad de los diferentes dueños del latifundio hacia los habitantes del pueblo se explica por la relación de este recurso natural con la dinámica económica porfirista, basada en la exportación de materias primas; ${ }^{30}$ pero también

${ }^{29}$ Simón Yiverino a Porfirio Díaz, México, 1 de octubre de 1906, CEHM, Fondo DCXXIII, legajo 23, carpeta 02, documento 14 .

${ }^{30}$ David Walker, “Una gran familia: la topografía social de Cuencamé, Durango, México, 1890-1930" (ponencia, XXI Congreso Internacional de la Asociación de Estudios Latinoamericanos, Chicago, Illinois, 1998), 19. Documento sin publicar en resguardo del Instituto de Investigaciones Históricas de la Universidad Juárez del Estado de Durango. Agradezco a la maestra María Guadalupe Rodríguez López, investigadora de dicho instituto, el haberme proporcionado esta información. 
dicho escenario explica que cuando Francisco Gómez Palacio negoció con los habitantes del pueblo y les ofreció que cultivaran tierra del latifundio a cambio de una parte de la cosecha, los enfrentamientos disminuyeran considerablemente. ${ }^{31}$

En la tierra del pueblo de Pasaje y zonas aledañas desde finales del siglo XIX se cultivaron productos que necesitaban grandes cantidades de agua, como maíz y frijol, mientras que la llegada del ferrocarril a la vez que ofreció nuevos mercados, al atravesar Santa Catalina del Álamo llevó a sus dueños a ejercer una mayor apropiación del territorio que consideraban su propiedad, no sólo para explotarlo mejor, sino para evitar cualquier peligro al nuevo flujo de mercancías. ${ }^{32}$ El ferrocarril al mismo tiempo que fue sinónimo de interconexión en el nivel macro, también lo fue de separación en el nivel micro, al aumentar las tensiones entre actores sociales que habían sido vecinos por muchos años.

La disputa por el agua de Pasaje se hizo patente desde la construcción del ferrocarril en el oriente de Durango. En 1891, como ya se mencionó, el gobernador de Durango, Juan Manuel Flores; el representante del Ferrocarril Internacional Mexicano, el señor L. M. Johnson; y el señor William Cook Scott, representante de la Compañía Limitada Mexicana de Hipotecas de Terrenos e Inversión, que era dueña de Santa Catalina del Álamo, acordaron, junto con la donación de los terrenos necesarios para construir la vía del tren, ${ }^{33}$ permitir a la compañía ferrocarrilera utilizar libremente todo el material que se encontrara sobre o debajo del terreno que le habían cedido, incluyendo los surcos o fuentes de agua; sólo quedó exenta de este uso la madera de la zona. ${ }^{34}$

${ }^{31}$ David Walker, "Los orígenes de la insurrección agraria en Cuencamé 1890-1910" (ponencia, Simposio Jack y Margaret Sweed, Universidad del Estado de Michigan, Departamento de Historia, Michigan, 2000), 17. Documento sin publicar en resguardo del Instituto de Investigaciones Históricas de la Universidad Juárez del Estado de Durango. Agradezco a la maestra María Guadalupe Rodríguez López, investigadora de dicho instituto, el haberme proporcionado esta información.

32 Walker, "Los orígenes de la insurrección...", 4.

${ }^{33}$ Se donaron 70 metros de ancho repartidos por mitad a uno y otro lado del eje de la vía troncal, a no ser que el terreno fuera labrado, en cuyo caso el ancho se reducía a 40 metros, repartidos de igual forma, mientras que el terreno para las estaciones del ferrocarril fue de 1200 metros de largo por 400 metros de ancho, repartidos a la mitad a uno y otro lado del eje de la vía.

${ }^{34}$ Acta de contrato y personalidad jurídica, Durango, 25 de septiembre de 1891, CEHM, Fondo DCXXIII, legajo 37, carpeta 02, documento 05. 
Durante la construcción del Ferrocarril Internacional Mexicano en el oriente de Durango se presentaron enfrentamientos entre los trabajadores de éste y los habitantes de distintos pueblos, quienes veían que se disponía de las tierras que habían ocupado por muchas generaciones. ${ }^{35}$ Parecía que en el Partido de Cuencamé la donación mencionada iba a desatar la violencia entre los habitantes de Pasaje, que consideraban el agua como parte de su propiedad, y la familia Martínez del Río, la que fue un paso más allá, ya que no sólo permitió que otros explotaran el agua en concesiones o donativos, sino que decidió explotarla ella misma para sus cultivos. En 1901 iniciaron la construcción de una presa en una de las haciendas que formaban el latifundio llamada Mercedes, para utilizar el agua de un afluente del Arroyo del Saucito llamado El Zorrillo (véase el mapa 3), el más importantes de los cuerpos de agua de la zona. Dicha fuente de agua se encontraba justo al lado del pueblo de Pasaje, por lo que la construcción de la presa imposibilitaría a sus habitantes hacer uso del mencionado líquido. ${ }^{36}$

Para noviembre de 1903 la producción del latifundio era más limitada que en las décadas anteriores, ya que se dividía entre la labor de temporal, principalmente frijol (que para esa fecha había dado malos resultados); la labor de riego, especialmente trigo y chile; así como la producción de lana y la cría de borregos finos. En lo correspondiente al agua, se indicaba que el depósito más grande tenía suficiente líquido para durar hasta finales de enero del año siguiente. Junto a esta labor productiva, en Santa Catalina del Álamo se encontraban en medio de las tareas de construcción de viviendas; Francisco Gómez Palacio resaltaba en sus informes que estaban haciendo acopio de materiales para albañiles y que las cuadrillas de éstos en 1903 habían sido igual de numerosas que en 1901 y 1902. Al mismo tiempo se informaba que los soldados que se encontraban en el latifundio habían sido retirados. $^{37}$

A partir de esta información se pueden observar dinámicas económicas y sociales interesantes. Por un lado queda claro que los almacenamientos de agua no eran suficientes, lo que en parte explicaría la poca diversificación

${ }^{35}$ Lorenzo M. Johnson a Juan Manuel Flores, Cd. Porfirio Díaz, 15 de mayo de 1893 , AHED, Fondo Secretaría General de Gobierno, Sección Siglo XIX, Serie Correspondencia de Gobernadores.

${ }^{36}$ Anexos al informe de la propiedad de Santa Catalina del Álamo y Anexas, s. 1., s. f., CEHM, Fondo DCXXIII, legajo 18, carpeta 02, documento 93, f. 22.

${ }^{37}$ Relación de actividades de la Hacienda de Santa Catalina del Álamo y Anexas, Santa Catalina, 28 de noviembre de 1903, CEHM, Fondo DCXXIII, legajo 18, carpeta 03, documento 68. 
en la producción del latifundio. Los Martínez del Río, al estar todavía concentrados en el cultivo de frijol, trigo, chile y la cría de borregos, mostraban que si bien podían colocar esos productos en otras latitudes gracias al ferrocarril, esta interconexión todavía no había modificado el sistema productivo interno del latifundio, ya que ésos eran los cultivos tradicionales de subsistencia de la región. Mientras que más al oriente, en la Comarca Lagunera, el centro de la actividad económica por sus redituables ganancias y su demanda en el exterior era el cultivo del algodón. ${ }^{38}$ En Santa Catalina del Álamo éste no se producía o, si se hacía, era en cantidades tan ínfimas que no merecía ser mencionado en los informes.

Podemos observar que hablar de conexión a través de los nuevos medios de transporte es engañoso, ya que si bien las vías férreas conectaron productores y consumidores, la relación entre inversión y características geográficas rediseñó la distancia y las fronteras de una manera más sutil. Si observamos el mapa 5, tanto Cuencamé como Torreón contaban con las vías que los conectaban con Estados Unidos, pero el hecho de que en el primero, específicamente en el latifundio de Santa Catalina del Álamo, no pudiera cultivarse algodón por los limitados recursos naturales, mantenía alejados a sus dueños de lo más dinámico del mercado estadounidense: acercamiento físico generado por el ferrocarril que promovía cambios en

${ }^{38}$ La Comarca Lagunera pasó de ser un territorio desértico de poca importancia durante gran parte del siglo XIX, a un eje económico destacado durante el Porfiriato, gracias a su conexión con importantes centros consumidores de materias primas como Monterrey, Chihuahua y Estados Unidos, lo cual derivó en el desarrollo de una importante industria algodonera que intentó monopolizar el control del agua y alteró el cultivo de alimentos, con sus respectivas consecuencias en la dinámica social. Para estudiar en profundidad el desarrollo económico que significó la producción de algodón en la Comarca Lagunera, véanse: Mario Cerutti, "Actividad económica y grupos empresariales en el norte de México a comienzos del siglo xx. El eje Chihuahua/La Laguna/Monterrey”, en El poder y el dinero. Grupos y regiones mexicanas en el siglo XIX, coord. de Beatriz Rojas (México: Instituto de Investigaciones Dr. José María Luis Mora, 1994); Mario Cerutti, "Redes y bolsones empresariales en el norte de México, 1870-1920", en La nostalgia y la modernidad, empresarios y empresas regionales de México. Siglos XIX y XX, coord. de María Guadalupe Rodríguez López (Durango: Universidad Juárez del Estado de Durango, Instituto de Investigaciones Históricas, 2005); Mario Cerutti, "Agricultura, agroindustria y tejido productivo-empresarial en La Laguna 1870-1915", en Historia del estado de Durango, v. III, Siglo XIX, coord. de María Guadalupe Rodríguez López (Durango: Universidad Juárez del Estado de Durango, Instituto de Investigaciones Históricas, 2013); y Guadalupe Villa Guerrero, "La industria algodonera, no textil, en el caso de la Compañía Industrial Jabonera de La Laguna”, en El poder y el dinero. Grupos y regiones mexicanas en el siglo XIX, coord. de Beatriz Rojas (México: Instituto de Investigaciones Dr. José María Luis Mora, 1994). 
los mercados, los cuales a su vez generaban diferencias en las dinámicas económicas.

Otro aspecto por destacar es el aumento de las labores de albañilería, las cuales habían permanecido constantes desde el inicio de la construcción de la presa El Zorrillo (como se le llamó originalmente). El incremento en la edificación de cuartos significa que estaba aumentando el número de trabajadores acasillados en el latifundio; fenómeno entendible si vemos que la producción en el lugar se concentraba en alimentos; esto era atractivo para peones que podían trabajar a cambio de recibir una porción de la cosecha. Pero también se explica por la demanda de mano de obra en la construcción de la presa, en donde los habitantes del pueblo de Pasaje pudieron encontrar una alternativa a la pérdida tanto de tierra como de agua, que irónicamente padecían a causa de la construcción de la misma presa. Esta información puede ayudar a explicar la falta de una respuesta violenta organizada de los habitantes de Pasaje frente a las labores de construcción. Si los administradores señalaron que los soldados que estaban en el latifundio habían sido retirados, se puede inferir que no consideraban que hubiera amenazas de ataques violentos que pudieran afectar las actividades que se llevaban a cabo en Santa Catalina del Álamo.

La presa fue proyectada por el ingeniero Carlos Patoni y la construcción fue dirigida en su mayor parte por el ingeniero Nicolás Durán. ${ }^{39}$ De 1901 a 1905 la edificación tuvo que hacer frente a distintos inconvenientes, no por actos de violencia de los vecinos de Pasaje, sino por las condiciones climatológicas. Durante el primer año de trabajo se presentaron diversas heladas, durante el segundo las precipitaciones pluviales fueron insignificantes, mientras que en los años posteriores se intercalaron las crecientes del afluente de El Zorrillo con la escasez de agua, lo que obligaba a detener las obras por cortos periodos. ${ }^{40}$

Otro factor que generó retrasos en las labores de construcción fue la inexperiencia de Nicolás Durán, que él mismo reconocía ${ }^{41}$ y que provocaba, según la opinión de Pablo Martínez del Río, que el ingeniero tuviera una conducta apática, renuencia a ejecutar los trabajos que se le encomendaban

${ }^{39}$ Anexos al informe de la propiedad de Santa Catalina del Álamo y Anexas, s. l., s. f., 26, CEHM, Fondo DCXXIII, legajo 18, carpeta 02, documento 93, f. 26.

${ }^{40}$ Anexos al informe de la propiedad de Santa Catalina del Álamo y Anexas, s. 1., s. f., 26, СЕНM, Fondo DCXXIII, legajo 18, carpeta 02, documento 93, f. 25.

${ }^{41}$ Carta de Nicolás Durán a Francisco Gómez Palacio, presa Las Mercedes, 25 de marzo de 1904, CEHM, Fondo DCXXIII, legajo 25, carpeta 02, documento 52. 
y una terquedad en sostener que tenía razón siempre, actitud que despertaba en quienes lo rodeaban una falta de confianza en su criterio. ${ }^{42}$ Esta situación se resolvió hasta agosto de 1905 cuando el ingeniero Durán presentó su renuncia al proyecto, aduciendo tanto problemas personales como otros planes profesionales que no había podido atender, asegurando que la presa al estar a punto de quedar concluida ya no requería su presencia. ${ }^{43} \mathrm{De}$ él se sabe que viajó en 1906 a Europa donde pasó un periodo de descanso antes de retomar sus estudios en México, ya que había sido aceptado en diversos cursos en la Escuela Nacional de Ingeniería. ${ }^{44}$ En lo que respecta a la presa Las Mercedes, fue concluida por el señor Pedro Barnetche, quien tuvo que realizar sólo trabajos mínimos, como excavaciones en ciertos tramos de las caídas de agua para direccionar el líquido a la presa o el reforzamiento de algunas puertas de ésta. ${ }^{45}$

En lo que respecta a las labores cotidianas, los documentos indican que "la presa fue construida enteramente por trabajadores nativos" - dato que apoya la idea de la incorporación de mano de obra proveniente del pueblo de Pasaje-, quienes contaban con poca maquinaria; debido a esto la mayoría de los materiales de construcción eran acarreados por carretillas tiradas por mulas y un pequeño tranvía. Una vez en la obra dichos materiales tenían que distribuirse por particulares y carretillas de mano. En lo que respecta al mortero, se mezclaba en una batidora movida por fuerza animal localizada a una milla de distancia en donde se encontraba agua procedente de las norias, para después ser traslada a la construcción en carros Decauville que también eran usados para el acarreo de la piedra desde la cantera. ${ }^{46}$

Las actividades descritas muestran todavía una preeminencia de los viejos esquemas de trabajo humano y animal por sobre la mecanización, lo cual explicaría por qué se detenían las obras cada vez que se desbordaba El Zorrillo o bajaba su afluente: las condiciones naturales determinaban la velocidad de una obra de ingeniería que se suponía iba a permitir a los

${ }^{42}$ Carta de Pablo Martínez del Río a Francisco Gómez Palacio, México, 3 de septiembre de 1905, СЕнм, Fondo DCXXIII, legajo 39, carpeta 03, documento 11.

${ }^{43}$ Carta de Nicolás Durán a Francisco Gómez Palacio, Durango, 27 de agosto de 1905, CEHM, Fondo DCXXIII, legajo 25, carpeta 02, documento 90.

${ }^{44}$ Carta de Nicolás Durán a Francisco Gómez Palacio, México, 27 de mayo de 1906, CEHM, Fondo DCXXIII, legajo 69, carpeta 03, documento 28.

${ }^{45}$ Informe acerca de los trabajos ejecutados en la presa de Las Mercedes, s. 1., 21 de agosto de 1906, СЕнм, Fondo DCXXIII, legajo 77, carpeta 03, documento 08.

${ }^{46}$ Informe acerca de los trabajos ejecutados en la presa de Las Mercedes, s. 1., 21 de agosto de 1906, CEHM, Fondo DCXXIII, legajo 77, carpeta 03, documento 08, fs. 24-25. 


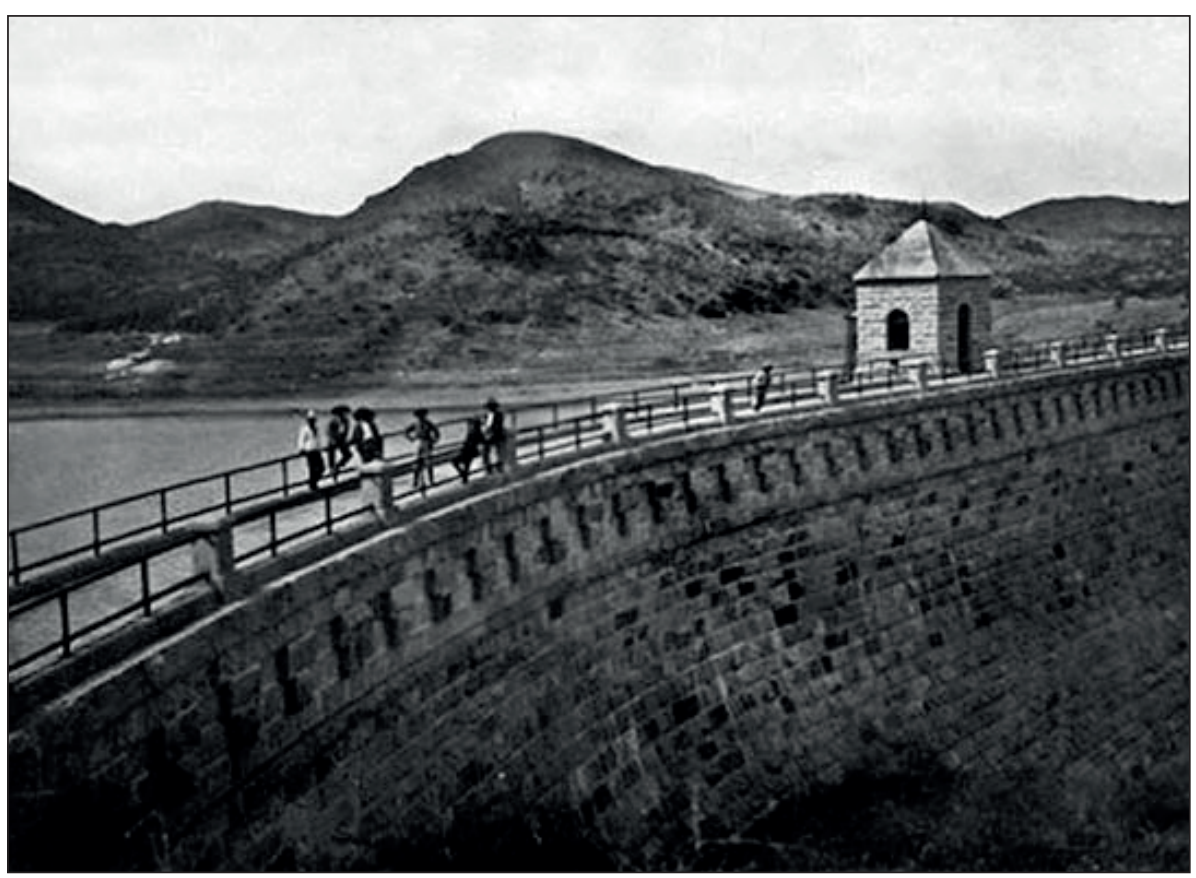

Figura 1. Cortina de la presa Las Mercedes.

Fuente: Fototeca del INAH. Delegación Durango

terratenientes no depender tanto de los caprichos de la madre naturaleza. La construcción de la presa se trataría de un territorio de frontera, entre una dinámica productiva y laboral propia de los tiempos anteriores a la llegada del ferrocarril, basada en una gran cantidad de hombres y animales, y otra posterior al tendido de las vías, en donde se buscaba usar la técnica para cambiar o aumentar lo que se cultivaba, lo que a su vez terminaría transformando la manera en que se trabajaba y las relaciones sociales aparejadas a esto. ${ }^{47}$

${ }^{47}$ El final del Porfiriato y el inicio de la Revolución mexicana fue la última etapa de un modelo de construcción de presas determinado por animales de carga, sobre todo a partir de que las presas tuvieron como finalidad primordial, además de acumular agua para la agricultura, la de generar energía eléctrica para la población cada vez más urbana de México, lo cual demandaba la mecanización del proceso de construcción. Para mayor información, véase Judith Domínguez, "La construcción de presas en México. Evolución, situación actual y nuevos enfoques para dar viabilidad a la infraestructura hídrica”, Gestión y Política Pública, n. 1 (2019), http://dx.doi.org/10.29265/gypp.v28i1.551. 
Por disposición de Pablo Martínez del Río, en marzo de 1904 se cambió el nombre de la nueva presa de El Zorrillo por el de Las Mercedes, ${ }^{48}$ seguramente en honor a su pequeña hija: Mercedes Martínez del Río y Vinent. La presa fue oficialmente inaugurada en septiembre de 1905, evento al que asistió el arzobispo de Durango, don Santiago de Zubiria y Manzanera, quien se encargó de la ceremonia religiosa, mientras que la madrina del evento fue la ya mencionada niña Mercedes. La obra concluida tenía una capacidad de almacenamiento de 14800000 metros cúbicos y una altura dese el lecho del arroyo de 32 metros, ${ }^{49}$ además de canales con una longitud de 8600 metros. ${ }^{50} \mathrm{El}$ costo total de la presa fue de 200000 pesos. ${ }^{51}$

\section{Consecuencias}

El potencial de irrigación de la presa dependía de la cantidad de agua que pudiera contener; teóricamente si estaba a su máxima capacidad podía regar una superficie de 2024 hectáreas; ;2 ${ }^{5}$ fortunadamente durante su proceso de construcción se registró el almacenamiento de la corriente dando un promedio de 11662532 metros cúbicos entre 1901 a 1905, mientras que la precipitación pluvial media fue de 427.6 milímetros durante los cinco años mencionados. ${ }^{53}$ Un dato que demuestra el gran potencial que tenía la presa para incrementar la productividad del latifundio es que las 2024 hectáreas que podía irrigar Las Mercedes representaban 58.16\% de los terrenos de riego de Santa Catalina del Álamo. ${ }^{54}$

Los informes de 1905 elaborados por los administradores del latifundio muestran cambios interesantes respecto a los de 1903. Señalan que se es-

${ }^{48}$ Carta de Nicolás Durán a Francisco Gómez Palacio, presa Las Mercedes, 25 de marzo de 1904, CEHM, Fondo DCXXIII, legajo 25, carpeta 02, documento 52.

${ }^{49}$ Memorándum sobre el comienzo y finalización de las obras de la presa de Las Mercedes, s. 1., s. f., CEHM, Fondo DCXXIII, legajo 25, carpeta 02, documento 95.

${ }^{50}$ Anexos al informe de la propiedad de Santa Catalina del Álamo y Anexas, s. 1., s. f., CEHM, Fondo DCXXIII, legajo 18, carpeta 02, documento 93, f. 26.

${ }^{51}$ Anexos al informe de la propiedad de Santa Catalina del Álamo y Anexas, s. 1., s. f., CEHM, Fondo DCXXIII, legajo 18, carpeta 02, documento 93, f. 23.

${ }^{52}$ Anexos al informe de la propiedad de Santa Catalina del Álamo y Anexas, s. 1., s. f., CEHM, Fondo DCXXIII, legajo 18, carpeta 02, documento 93, f. 26.

53 Anexos al informe de la propiedad de Santa Catalina del Álamo y Anexas, s. 1., s. f., CEHM, Fondo DCXXIII, legajo 18, carpeta 02, documento 93, f. 25.

${ }^{54}$ Informe sobre la inspección verificada en Santa Catalina del Álamo y Anexas, s. 1., mayo de 1926, CEHM, Fondo DCXXIII, legajo 18, carpeta 02, documento 90. 
taba regando el trigo día y noche, además de que en la labor de El Zorrillo se comenzaba a sembrar papa; si tomamos en cuenta que estos dos cultivos son conocidos por necesitar de grandes y constantes suministros de agua para ser rentables, podemos ver que Las Mercedes significó en un inicio la posibilidad de aumentar y diversificar la producción del latifundio, en donde ya no sólo se cultivaban alimentos. Para 1905 los Martínez del Río ya producían guayule, el cual vendían a la Continental Mexican Rubber, empresa de capital estadounidense. ${ }^{55}$

Desde principios del siglo XIX hay registros de la presencia de la planta del guayule en la mayoría de los estados del noreste de México. ${ }^{56} \mathrm{El}$ inicio de su explotación a gran escala a principios del siglo $\mathrm{xx}$ fue debido a que la goma que producía tenía cualidades similares al hule, por lo que ésta podía ser utilizada en la fabricación de neumáticos en la industria automovilística estadounidense que se hallaba al alcance gracias al ferrocarril. Esta planta, al encontrarse en zonas desérticas, revalorizó la tierra que hasta finales del siglo Xix se consideraban de poca calidad, la cual no había llamado la atención de los terratenientes. ${ }^{57}$

Otro cambio importante que se observa en la producción de Santa Catalina del Álamo a partir de la puesta en funcionamiento de Las Mercedes fue la siembra de algodón. Para 1907 este cultivo se había generalizado en la hacienda Mercedes, pero con la importante distinción de que mientras el algodón de los Martínez del Río se desarrollaba adecuadamente, el de los aparceros tenía problemas de plagas. Es importante destacar que en ese año la presa Las Mercedes tenía agua que llegaba a los 18.1 metros de altura, ${ }^{58}$

${ }^{55}$ Informe de Santa Catalina del Álamo, Estación de Pasaje, 12 de marzo de 1905, CEHM, Fondo DCXXIII, legajo 31, carpeta 03, documento 44.

${ }^{56}$ Los estados en donde se ha encontrado la presencia del guayule además de Durango son San Luis Potosí, Zacatecas, Chihuahua, Coahuila, Nuevo León y el sur de Texas en los Estados Unidos.

${ }^{57}$ Para más información sobre la importancia del guayule en la economía mexicana, sobre su relación con los mercados europeos y estadounidense en los primeros años del siglo $\mathrm{xx}$, así como de las características de su cultivo y cuidado, véase Julio Morpurgo, Los sucedáneos de la goma elástica y el guayule en México. Monografía publicada con motivo de la inauguración del primer muestrario de productos de México en Trieste, 1908 (México: Secretaría de Fomento, 1910); y Daniel Guillermo Rodríguez Barragán, “El papel del guayule en el desarrollo económico y el aumento de las tensiones sociales en Cuencamé, Durango, al inicio del siglo xx", Peldaños de la Historia, Boletín del Archivo Histórico del Archivo General del Poder Ejecutivo de Guanajuato, n. 2 (2017), 71-97.

${ }^{58}$ Reporte de los trabajos en la Hacienda de Santa Catalina del Álamo, Hacienda Las Mercedes, 23 de julio de 1907. CEHM, Fondo DCXXIII, Legajo 26, Carpeta 02, Documento 57. 
es decir, que estaba a $56.56 \%$ de su capacidad, lo que resulta contrastante con el escenario regional, ya que 1906-1907 fue un periodo que se caracterizó por una crisis de producción agrícola y una fuerte sequía en Durango. ${ }^{59}$

Construir la presa sin duda ayudó económicamente a los Martínez del Río, les permitió aumentar y diversificar su producción de tal manera que pudieron insertarse con todo su potencial en la dinámica económica abierta por el ferrocarril, pudieron superar el muro que el tendido de las vías había puesto entre la demanda de materias primas para la industria y los terratenientes que únicamente se dedicaban a los cultivos tradicionales como maíz y frijol. Pero estas ventajas se consiguieron a costa de aumentar las tensiones sociales en el escenario inmediato: se derribó una frontera económica entre consumidores y productores, pero se levantó otra entre latifundistas y habitantes de los pueblos.

Los habitantes de Pasaje también se vieron afectados, pero de forma negativa, por el fin de la construcción de la presa y su puesta en funcionamiento: los fenómenos climatológicos como las sequías hicieron que se resintiera el acaparamiento del agua por parte del latifundio, el cual, a partir de la revalorización de la tierra de poca calidad gracias al guayule, comenzó a expandirse apropiándose de la última tierra que conservaban en Pasaje. ${ }^{60}$ La llegada de una producción no alimenticia (guayule y algodón) provocó que el arrendamiento de tierra fuera menos rentable para el terrateniente ${ }^{61}$ lo que hizo más difícil la condición de aparcero, al no recibir una parte de la cosecha, sino un salario insuficiente ${ }^{62}$ a esto hay que sumar el

${ }^{59}$ Carta de Francisco Gómez Palacio a Pablo Martínez del Río, Durango, 17 de julio de 1907, CEHM, Fondo DCXXIII, caja 02.

${ }^{60}$ Para el estudio sobre la expansión de los latifundios a partir de la ocupación de tierra de mala calidad por el aumento de la demanda de guayule, los conflictos sociales generados por esto, así como el abandono de la siembra de alimentos como maíz y frijol para ser sustituidos por dicha planta y sus consecuencias sociales, véase Guadalupe Villa Guerrero, "Riqueza en suelo eriazo. La industria guayulera y los conflictos interregionales de la elite norteña en México", Secuencia: Revista de Historia y Ciencias Sociales, n. 46 (2000): 93-120, https://doi.org/10.18234/secuencia.v0i46.677

${ }^{61}$ Carta de Tomás L. Campbell a Francisco Gómez Palacio, Cuencamé, 3 de agosto de 1908, CEHM, Fondo DCXXIII, caja 03.

${ }^{62}$ A principios del siglo xx en el oriente de Durango en promedio un administrador de una hacienda podía ganar hasta 50 pesos mensuales; un mayordomo de labor, 10; un peón para acarreo de paja, 3.50; un peón para corte de madera, 2.25. Para más información, véase Guadalupe Villa Guerrero, "Élites y Revolución en Cuencamé, Durango. El caso de la familia López Negrete” (tesis doctoral, Universidad Nacional Autónoma de México, 2005), 28-40. 
aumento de trabajadores que competían por un lugar en las haciendas. ${ }^{63}$ Conforme avanzó la primera década del siglo xx las opciones se les fueron acabando a los habitantes de Pasaje.

En la última etapa del Porfiriato, Santa Catalina del Álamo había regresado a la diversificación productiva de mediados del siglo XIX, se seguía produciendo maíz y frijol en Santa Catalina y se criaba ganado en Álamo y Covadonga, pero las joyas de la corona de los Martínez del Río ya eran las haciendas de Mercedes y Pasaje que se dedicaban a producir algodón la primera y guayule la segunda. ${ }^{64}$ Para 1910 el Partido de Cuencamé producía $50.52 \%$ de todo el guayule de Durango y el latifundio de los Martínez del Río era el segundo mayor productor en dicho partido con las 1750 toneladas que generó ese año. ${ }^{65}$ Este desarrollo económico, aparente muestra del éxito de la conexión con los mercados extranjeros y la utilización de la presa Las Mercedes, sólo enmascaraba una gran inconformidad social que llevó a miembros del pueblo de Pasaje a participar en la revolución maderista.

Desde 1911 porciones del latifundio de Santa Catalina del Álamo fueron ocupadas tanto por habitantes de Pasaje como de otras localidades, lo que se generalizó a toda la propiedad en 1913 después de que las tropas villistas tomaron la capital del estado. ${ }^{66} \mathrm{Al}$ mismo tiempo que se realizaba dicha ocupación de facto, los habitantes de Pasaje intentaron legalizarla. En enero de 1912 una delegación formada por Antonio Castellanos y José Floylán Reyes a nombre de los vecinos de Peñón Blanco, José María Carreón Rodríguez y Pedro R. Sosa por el pueblo de Pasaje y Agustín Aguilar y José María Martínez por los habitantes de Santa Clara, entre otros, visitaron al presidente Francisco I. Madero en la ciudad de México para pedir la restitución de sus tierras; recibieron por parte del titular del ejecutivo promesas de que se cumpliría la ley pero no acciones concretas. ${ }^{67}$

${ }^{63}$ Carta de Manuel Castellanos a Francisco Gómez Palacio, s. 1., 20 de febrero de 1906, CEHM, Fondo DCXXIII, caja 03.

${ }^{64}$ Walker, "Un estudio estadístico de la economía agrícola...”, 19.

${ }^{65}$ Memoria presentada al $\mathrm{H}$. Congreso del estado por el gobierno del mismo, sobre los actos de administración pública durante el periodo del 16 de septiembre de 1908 al 16 de septiembre de 1910, imprenta de la Mariposa, Durango, 1910, Anexo 82, AHED, Fondo Secretaría de Gobierno, Sección Archivo.

${ }^{66}$ Carta de Amelia Zamacona de Martínez del Río a José Y. Limantour, México, 16 de noviembre de 1913, СЕHм, Fondo CDLIV, Serie 2a., caja 17.

${ }^{67}$ Acta de protesta firmada por Antonio Castellanos y José Floylán Reyes, representantes del pueblo de Peñón Blanco, 12 de enero de 1912, AHED, Correspondencia, caja sin clasificar. 
A partir de esa entrevista se pierde la pista de los habitantes de Pasaje hasta el 13 de junio de 1916, cuando Severino Ceniceros se incorporó a las fuerzas carrancistas al frente de un contingente de habitantes de dicha comunidad. ${ }^{68}$ Esta decisión se comprende si tomamos en cuenta que Venustiano Carranza había dado a conocer en enero del año anterior su ley agraria, la cual en un escenario como el del oriente de Durango en donde el villismo ya no representaba una alternativa viable de gobierno, se convirtió en la esperanza de los trabajadores rurales que habían ocupado los diversos latifundios.

En los años posteriores los terratenientes de Cuencamé se vieron obligados a dividir legalmente sus propiedades, aunque muchos de ellos lo hicieron de manera meramente formal con ventas de porciones de sus latifundios entre sus familiares más cercanos. ${ }^{69}$ En lo que respecta a los descendientes de Pablo Martínez del Río - quien murió en 1907-, también tuvieron que dividirse Santa Catalina del Álamo. En los registros de 1923 la hacienda de Santa Catalina pertenecía legalmente a Pablo Martínez del Río y Vinet; la de Álamo, a María Josefa de Martínez del Río; Covadonga, a Dolores Asúnsolo Martínez del Río; y Cruces, a Jaime Martínez del Río. ${ }^{70}$

Dicha estrategia de dividir las propiedades, para que legalmente no fueran consideradas como latifundios y por lo tanto objeto de la reforma agraria, a la larga no surtió efecto. Durante las décadas de los veinte y treinta se llevó a cabo el reparto de tierras en el oriente de Durango lo que reavivó los conflictos por el agua, esta vez entre los pueblos y los centros poblacionales que querían convertirse en ejidos, como lo muestra la dotación de agua de riego hecha a los vecinos del pueblo de Pedriceña sobre las aguas de los Arroyos, El Zorrillo y Cuencamé en febrero de 1928, ${ }^{71}$ dicho pueblo había recibido dotación de tierras en 1925 en detrimento de Santa Catalina del Álamo, a partir de lo cual recibía agua de El Zorrillo previo a su llegada a Las Mercedes. ${ }^{72}$ Un año después de esta dotación, el 2 de febre-

${ }^{68}$ Carta de Álvaro Obregón a Severino Ceniceros, México, 28 de junio de 1916, AHED, Correspondencia, caja sin clasificar.

${ }^{69}$ David Walker, "El Durango posrevolucionario", en Porfiriatio y revolución en Durango, coord. de Gloria Estela Cano Cooley y Mario Cerutti (México: Universidad Juárez del Estado de Durango, Instituto de Investigaciones Históricas, 1999), 255.

70 Walter, “El Durango posrevolucionario...”, 261.

71 "Notificación a los usuarios de las aguas de los arroyos El Zorrillo y Cuencamé”, Diario Oficial, México, 2 de febrero de 1928.

72 Fallo relativo a la dotación del ejido Pedriceña, Cuencamé, Durango, 30 de julio de 1925, Archivo General Agrario (en adelante AGA), Expediente del ejido Pedriceña, Cuencamé, Durango. 
ro de 1929, las aguas del arroyo El Zorrillo al pertenecer a un sistema hidrográfico que atravesaba dos estados de la república (Durango y Coahuila) fueron declaradas de propiedad nacional. ${ }^{73}$

En el caso del pueblo de Pasaje las tierras que recibió no fueron en dotación sino una restitución que se ejecutó oficialmente el 13 de mayo de 1921 en donde se reconoció la tierra que estaba en litigio con los Martínez del Río (75 826 hectáreas), ${ }^{74}$ pero no toda la que los habitantes reclamaban como propia y que según ellos se les había arrebatado desde 1807, es decir, al pueblo de Pasaje se le reconoció como propia la porción del latifundio de Santa Catalina del Álamo que había ocupado durante la revolución, pero no la que los Martínez del Río les habían quitado para construir Las Mercedes. ${ }^{75}$

Dicha decisión se explica si tomamos en cuenta que alrededor de la presa Las Mercedes se habían reunido núcleos poblacionales constituidos por extrabajadores provenientes de lugares como Velardeña que demandaban tierra. De esta forma alrededor de la presa se crearon dos ejidos, los cuales fueron dotados de tierra por el gobierno federal el mismo día, el 31 de enero de 1930. Al primero, el ejido Mercedes, constituido por antiguos aparceros que cultivaban las tierras en la extremidad del canal de riego de la presa, se le dotó de 4414 hectáreas. ${ }^{76} \mathrm{Al}$ otro ejido, denominado La Fe, compuesto por antiguos trabajadores del latifundio que se asentaron en el margen derecho del arroyo El Zorrillo, se le otorgó 1740 hectáreas; esas tierras eran las más beneficiadas por la presa Las Mercedes. ${ }^{77} \mathrm{~A}$ pesar de su cercanía a la presa, los expedientes de ambos ejidos señalan que sus habitantes no tenían la capacidad técnica para aprovechar este depósito de agua en todo su potencial.

La presa Las Mercedes pasó a ser propiedad nacional el 17 de diciembre de 1928, lo que no detuvo la lucha entre los ejidatarios de Pasaje, Mercedes y La Fe por apropiarse de la mayor cantidad posible de agua. El 3 de septiembre de 1936 por resolución presidencial se le otorgó al ejido Mercedes

73 "Declaración de propiedad nacional del arroyo El Zorrillo o La Vieja”, Diario Oficial, México, 2 de febrero de 1929.

${ }^{74}$ Fallo relativo a la restitución de ejidos al pueblo de Pasaje, Cuencamé, Durango, 13 de mayo de 1921, AGA, Expediente del ejido El Pasaje, Cuencamé, Durango.

${ }^{75}$ Fallo relativo a la restitución de ejidos al pueblo de Pasaje, Cuencamé, Durango, 13 de mayo de 1921, AGA, Expediente del ejido El Pasaje, Cuencamé, Durango, f. 19.

${ }^{76}$ Acta de posesión de ampliación, 9 de octubre de 1952, AGA, Expediente del ejido Las Mercedes, Cuencamé, Durango.

${ }^{77}$ Fallo relativo a la dotación del ejido La Fe, Cuencamé, Durango, 31 de enero de 1930, AGA, Expediente del ejido La Fe, Cuencamé, Durango. 
40\% del agua de la presa, es decir, 789600 metros cúbicos. Más de diez años después, en 1947, se repartió el agua restante; a Pasaje le correspondió $31.1 \%$ mientras que a La Fe le tocó $28.9 \%{ }^{78}$ En las décadas siguientes, mientras se ampliaban los ejidos requerían más agua, ${ }^{79}$ por lo que las disputas entre ellos prosiguieron hasta 1983 cuando se modificó la cantidad de agua que recibían al adjudicarle a Pasaje 3418181 metros cúbicos, muy por encima de los 613914 metros cúbicos que había recibido en $1947,{ }^{80}$ lo que demuestra la renovada capacidad de almacenamiento de la presa.

Cuando fue construida Las Mercedes, en el estado la consideraron la presa privada más grande del mundo. ${ }^{81}$ Conservó esta buena imagen en la década de los veinte, al grado de que el ilustre ingeniero Pastor Rouaix la calificó como "el único depósito de agua verdadero que tiene el estado de Durango". ${ }^{2}$ Pero el adelanto tecnológico que representó ocultaba una realidad social muy compleja, cuyos cambios por la construcción de dicha obra no se dimensionaron en su momento, sino que solamente se tomó en cuenta su potencial económico. La presa les permitió a los Martínez del Río explotar en todo su potencial Santa Catalina del Álamo, pero también generó un enfrentamiento por el agua que la participación de los habitantes de Pasaje y lugares aledaños en la Revolución no resolvió, sino que reconfiguró, estableciendo tensas relaciones entre ejidatarios, pueblos y gobierno federal. En la actualidad Las Mercedes está incluida en la lista de las principales presas del estado de Durango, sigue dando servicio, ${ }^{83}$ como un mudo testigo del Porfiriato, la Revolución y el reparto agrario.

78 "Resolución en el expediente de dotación de aguas al poblado La Fe, en Cuencamé, Durango”, Diario Oficial, México, 11 de octubre de 1947.

${ }^{79} \mathrm{La}$ Fe tuvo una primera ampliación en 1944 de 2757 hectáreas y una segunda en 1954 de 1635 hectáreas; en cuanto a Las Mercedes su primera ampliación fue en 1944 de 2220 hectáreas y la segunda en 1952 de 3453 hectáreas; mientras que Pasaje tuvo su primera ampliación en 1930 de 9878 hectáreas; una segunda en 1945 de 3750 hectáreas y una tercera en 1952 de 2600 hectáreas. Padrón e Historial de Núcleos Agrarios (PHINA), https:// phina.ran.gob.mx/index.php.

80 "Resolución sobre acción de dotación de aguas, solicitada por vecinos del poblado denominado Pasaje, ubicado en el municipio de Cuencamé, Durango”, Diario Oficial, México, 30 de agosto de 1983.

${ }^{81}$ Patricia Fernández de Castro, "Derechos de propiedad y tenencia de la tierra”, en Porfiriato y Revolución en Durango, coord. de Gloria Cano Cooley y Mario Cerutti (Durango: Universidad Juárez del Estado de Durango, Instituto de Investigaciones Históricas, 1992), 14-15.

${ }^{82}$ Rouaix, Geografía del estado de Durango..., 154.

${ }^{83}$ Gloria Estela Cano Cooley, "Las fincas rústicas del estado de Durango según los padrones catastrales de 1898. Un recuento de sus tierras laborables, ganados, extensiones 


\section{FUENTES}

Archivos

Archivo General Agrario (AGA).

Archivo Histórico del Estado de Durango (AHED).

Archivo Porfirio Díaz de la Universidad Iberoamericana (APD).

Centro de Estudios de Historia de México del Grupo Carso (сенм).

\section{Hemerografía}

Diario Oficial (México) 1928, 1929, 1947, 1983.

Periódico Oficial del Gobierno del Estado de Durango (Durango) 1905.

\section{Recursos electrónicos}

Padrón e Historial de Núcleos Agrarios (PHinA), consultado el 10 de febrero de 2020. https://phina.ran.gob.mx/index.php.

\section{Bibliografía}

Arreola Valenzuela, Antonio. "Construcción del sistema ferroviario e inversión estadounidense en Durango." En Historia del estado de Durango. V. III, Siglo XIX, coordinación de María Guadalupe Rodríguez López, 398-433. Durango: Universidad Juárez del Estado de Durango, Instituto de Investigaciones Históricas, 2013.

Arreola Valenzuela, Antonio. Durango, más de un siglo sobre rieles. Durango: Universidad Juárez del Estado de Durango, Instituto de Investigaciones Históricas, 1992.

Cano Cooley, Gloria Estela (2013). "Las fincas rústicas del estado de Durango según los padrones catastrales de 1898. Un recuento de sus tierras laborables, ganados, extensiones territoriales y valores catastrales.” En Historia del estado de Durango. V. III, Siglo XIX, coordinación de Guadalupe Rodríguez López, 472-545.

territoriales y valores catastrales”, en Historia del estado de Durango, v. III, Siglo XIX, coord. de Guadalupe Rodríguez López (Durango: Universidad Juárez del Estado de Durango, Instituto de Investigaciones Históricas, 2013), 482. 
Durango: Universidad Juárez del Estado de Durango, Instituto de Investigaciones Históricas, 2013.

Cerutti, Mario. "Actividad económica y grupos empresariales en el norte de México a comienzos del siglo xx. El eje Chihuahua/La Laguna/Monterrey." En El poder y el dinero. Grupos y regiones mexicanas en el siglo XIX, coordinación de Beatriz Rojas, 330-362. México: Instituto de Investigaciones Dr. José María Luis Mora, 1994.

Cerutti, Mario. "Agricultura, agroindustria y tejido productivo-empresarial en La Laguna 1870-1915." En Historia del estado de Durango. V. III, Siglo XIX, coordinación de María Guadalupe Rodríguez López, 298-341. Durango: Universidad Juárez del Estado de Durango, Instituto de Investigaciones Históricas, 2013.

Cerutti, Mario. "Redes y bolsones empresariales en el norte de México, 1870-1920." En La nostalgia y la modernidad, empresarios y empresas regionales de México. Siglos XIX y XX, coordinación de María Guadalupe Rodríguez López, 27-96. Durango: Universidad Juárez del Estado de Durango, Instituto de Investigaciones Históricas, 2005.

Cramaussel, Chantal. Poblar la frontera: la provincia de Santa Bárbara en Nueva Vizcaya durante los siglos XVI y XVII. Zamora: El Colegio de Michoacán, 2006.

Domínguez, Judith. "La construcción de presas en México. Evolución, situación actual y nuevos enfoques para dar viabilidad a la infraestructura hídrica." Gestión y Política Pública, n. 1 (2019): 3-37. http://dx.doi.org/10.29265/gypp. v28i1.551.

Fernández de Castro, Patricia. "Derechos de propiedad y tenencia de la tierra." En Porfiriato y Revolución en Durango, coordinación de Gloria Cano Cooley y Mario Cerutti, 1-34. Durango: Universidad Juárez del Estado de Durango, Instituto de Investigaciones Históricas, 1992.

Gerhard, Peter. La frontera norte de la Nueva España. México: Universidad Nacional Autónoma de México, Instituto de Investigaciones Históricas, 1996.

Hart, John. "Durango: el crecimiento del capitalismo norteamericano durante el porfiriato." En Historia del estado de Durango. V. III, Siglo XIX, coordinación de María Guadalupe Rodríguez López, 378-397. Durango: Universidad Juárez del Estado de Durango, Instituto de Investigaciones Históricas, 2013.

Morpurgo, Julio. Los sucedáneos de la goma elástica y el guayule en México. Monografía publicada con motivo de la inauguración del primer muestrario de productos de México en Trieste, 1908. México: Secretaría de Fomento, 1910.

Rodríguez Barragán, Daniel Guillermo. "El papel del guayule en el desarrollo económico y el aumento de las tensiones sociales en Cuencamé, Durango, al inicio del siglo xx." Peldaños de la Historia. Boletín del Archivo Histórico del Archivo General del Poder Ejecutivo de Guanajuato, n. 2 (2017): 71-97. 
Romero Navarrete, Lourdes. "Conflicto y negociación por el agua del Nazas, 18881936. Del dominio público a la propiedad nacional.” Región y Sociedad, n. 36 (2006): 147-176. https://doi.org/10.22198/rys.2006.36.a587.

Rouaix, Pastor. Geografía del estado de Durango. México: Secretaria de Agricultura y Fomento, 1929.

Salmerón Sanginés, Pedro. La División del Norte. La tierra, los hombres y la historia de un ejército del pueblo. México: Planeta, 2006.

Uhthoff, Luz María. "La American Smeltine and Refining Co. (AsArCo) en México 1890-1930." Tesis de licenciatura. Universidad Nacional Autónoma de México, 1983.

Vallebueno Garcínava, Miguel Felipe de Jesús. "Epidemias y crisis de subsistencia en Durango. 1622-1918." En Historia del estado de Durango. V. III, Siglo XIX, coordinación de María Guadalupe Rodríguez López, 124-167. Durango: Universidad Juárez del Estado de Durango, Instituto de Investigaciones Históricas, 2013.

Vallebueno Garcínava, Miguel Felipe de Jesús. Haciendas de Durango. Durango: Gobierno del Estado de Durango/Tonalco/Universidad Juárez del Estado de Durango, 1997.

Vargas-Lobsinger, María. Formación y decadencia de una fortuna: los mayorazgos de San Miguel de Aguayo y San Pedro del Álamo, 1583-1823. México: Universidad Nacional Autónoma de México, Instituto de Investigaciones Históricas, 1992. Villa Guerrero, Guadalupe. "Élites y Revolución en Cuencamé, Durango. El caso de la familia López Negrete.” Tesis doctoral. Universidad Nacional Autónoma de México, 2005.

Villa Guerrero, Guadalupe. "La industria algodonera, no textil, en el caso de la Compañía Industrial Jabonera de La Laguna.” En El poder y el dinero. Grupos y regiones mexicanas en el siglo XIX, coordinación de Beatriz Rojas, 288-305. México: Instituto de Investigaciones Dr. José María Luis Mora, 1994.

Villa Guerrero, Guadalupe. “¿Interés público o beneficio particular? El agua en la Comarca Lagunera (1881-1910).” Secuencia. Revista de Historia y Ciencias Sociales, n. 39 (1997): 41-48. https://doi.org/10.18234/secuencia.v0i39.590.

Villa Guerrero, Guadalupe. "Riqueza en suelo eriazo. La industria guayulera y los conflictos interregionales de la elite norteña en México.” Secuencia. Revista de Historia y Ciencias Sociales, n. 46 (2000): 93-120. https://doi.org/10.18234/ secuencia.v0i46.677.

Walker, David. "El Durango posrevolucionario.” En Porfiriatio y revolución en Durango, coordinación de Gloria Estela Cano Cooley y Mario Cerutti, 225-286. México: Universidad Juárez del Estado de Durango, Instituto de Investigaciones Históricas, 1999. 
Walker, David. "Un estudio estadístico de la economía agrícola de Cuencamé, México: 1895-1911.” Ponencia presentada en el Taller de Historia Económica. Universidad de Indiana, Bloomington, Indiana, 1996.

Walker, David. "Una gran familia: la topografía social de Cuencamé, Durango, México, 1890-1930." Ponencia presentada en el XXI Congreso Internacional de la Asociación de Estudios Latinoamericanos, Chicago, Illinois, 1998.

Walker, David. "Los orígenes de la insurrección agraria en Cuencamé 1890-1910." Ponencia presentada en el Simposio Jack y Margaret Sweed. Universidad del Estado de Michigan, Departamento de Historia, Michigan, 2000.

Walker, David. Parentesco, negocios y política. La familia Martínez del Río en México, 1823-1867. México: Alianza Editorial, 1991.

Walker, David. "Un terrateniente urbano en Durango 1897-1911." Ponencia presentada en la Universidad de Radford. Virginia, s. f.

\section{SOBRE EL AUTOR}

Licenciado en Ciencias Políticas y maestro en Ciencias y Humanidades con especialidad en Historia por la Universidad Juárez del Estado de Durango. Actualmente es catedrático de la Facultad de Derecho y Ciencias Políticas en la misma universidad. 